\section{BMJ Paediatrics Open}

\title{
Associations between parental mental health and other family factors and healthcare utilisation among children and young people: a retrospective, cross- sectional study of linked healthcare data
}

\author{
Kathryn Dreyer, ${ }^{1}$ Robert A P Williamson, ${ }^{1}$ Dougal S Hargreaves, ${ }^{2}$ Rebecca Rosen, ${ }^{3}$ \\ Sarah R Deeny ${ }^{1}$
}

To cite: Dreyer K, Williamson RAP, Hargreaves DS, et al. Associations between parental mental health and other family factors and healthcare utilisation among children and young people: a retrospective, cross-sectional study of linked healthcare data. BMJ Paediatrics Open 2018;2:e000266. doi:10.1136/ bmjpo-2018-000266

- Additional material is published online only. To view please visit the journal online (http://dx.doi.org/10.1136/ bmjpo-2018-000266).

Received 8 February 2018 Revised 24 May 2018 Accepted 28 May 2018
Check for updates

${ }^{1}$ Data Analytics, The Health Foundation, London, UK ${ }^{2}$ UCL Great Ormond Street Institute of Child Health, London, UK

${ }^{3}$ Valentine Health, London, UK

Correspondence to Ms Kathryn Dreyer; kathryn. dreyer@health.org.uk

\section{ABSTRACT}

Objective To identify the degree to which parental diagnosis of depression or other long-term conditions, parental health-seeking behaviours and household factors were associated with a healthcare utilisation among children and young people (CYP) ( $0-15$ years).

Design Retrospective, cross-sectional study of electronic health records, from 25252 patients registered at a large, London-based primary care provider. The associations between children's healthcare utilisation and the characteristics of the child, their parents/carers and their household structure were examined using multivariable regression.

Results Controlling for parental utilisation, parental depression (vs not) was significantly associated with increased healthcare utilisation for CYP. Odds ratios for CYP with siblings $=1.41(95 \% \mathrm{Cl} 1.10$ to 1.80$)$ for emergency department (ED) attendances, 1.67 (95\% Cl 1.32 to 2.11) for outpatient appointments, 1.47 (95\% Cl 1.07 to 2.03) for inpatient admission, and rate rato $=1.28(95 \% \mathrm{Cl} 1.04$ to 1.78) for general practitioner (GP) consultations. After adjusting for child and parental characteristics, parental general practice attendance (+1 from mean) was predictive of increased CYP general practice attendance, rate ratio 1.07 (95\% Cl 1.06 to 1.08) for CYP with siblings. Parental ED attendance also increased the risk of CYP ED attendance, with OR 1.27 (95\% Cl 1.12 to 1.44) for CYP with siblings.

Conclusions Parental depression is associated with increased utilisation of ED, outpatient and inpatient services by CYP, as well as with increased GP consultations among adolescents. Our results demonstrate that healthcare utilisation by CYP is associated with the healthseeking behaviour of adults in their household.

\section{INTRODUCTION}

The rising rates of emergency department attendance and inpatient admissions in children and young people in England $^{1}$ are of concern to clinicians and policy makers. While much emergency and inpatient care is often an appropriate form of treatment,

\section{What is already known on this topic?}

An association between parental self-reported healthcare utilisation and parent-reported patterns of child utilisation has been demonstrated using survey data and self-reported health and care information.

- No existing studies examine the association between child healthcare utilisation and parental health, accounting for the adults and siblings within a household and their underlying healthcare usage patterns.

\section{What this study hopes to add?}

After adjusting for child and parental characteristics, parental depression is associated with $41 \%$ increased odds of emergency department (ED) attendance, $47 \%$ increased odds of inpatient admission and $67 \%$ increased odds of outpatient appointments in children and young people (CYP).

- After controlling for other factors, parental utilisation of general practice appointments and ED attendance increase the risk of children and young people's utilisation of these services.

increasing rates of care in an acute setting results in high and potentially avoidable spending. There are also wider opportunity costs, such as scarce skilled paediatric staff being based in hospitals delivering acute care, rather than in community settings delivering preventive care and health promotion.

Numerous studies have shown that interventions and new models of care have significant potential to reduce demand for emergency department attendance. ${ }^{2-6}$ However, it has proved difficult to realise these reductions in practice, which may reflect lack of research 
or interventions to address wider determinants of healthcare seeking behaviour among children.

While there has been extensive research into the role that health inequalities play in healthcare activity ${ }^{78}$ and into system-level factors that influence emergency admissions, ${ }^{49}$ there has been little consideration as to the influence that family context might play on the healthcare utilisation of children. There is some evidence that family context may have an important role influencing the healthcare utilisation and needs of their children, through the availability of knowledge, skills, social support ${ }^{10-12}$ and health-seeking behaviour and preferences. ${ }^{13}$ Poor parental mental health is associated with negative health outcomes for children, ${ }^{14}$ and parental anxiety is a contributing factor to a child's utilisation of healthcare services. ${ }^{15}$ Furthermore, shared genetic risks and the wider social determinants in the household ${ }^{16}$ could account for a clustering of health behaviours in households. However, there has been surprisingly little focus on family context and the role this plays on child healthcare activity.

A large portion of the evidence regarding the impact of parental health on children's healthcare utilisation comes from small, retrospective studies, relying on self-reported health and care information, ${ }^{17-19}$ and survey data where parents report their previous healthcare utilisation. ${ }^{20-22}$ Few studies have used person-level data from electronic health records in primary care. Previous studies failed to account for all aspects of parental health, with some focusing on specific long-term conditions ${ }^{10} 1923$ or only examining one parent. ${ }^{1021}$ Furthermore, there is limited evidence from countries with healthcare systems that are free at the point of use and offer universal coverage, as most analyses originate from the insurance-based US system. ${ }^{13} 18192123$

In this paper, we analyse electronic health records from 25252 patients registered at a primary care provider in London. We created household groups by identifying patients living at the same address, and then modelled the impact of parental healthcare utilisation and longterm conditions on four types of children's healthcare utilisation (general practice appointments, emergency department attendance, inpatient admissions and outpatient appointments), controlling for child, parental and household characteristics.

\section{METHODS}

\section{Study setting, dataset, inclusion and exclusion criteria}

Our dataset contained electronic health records from 25252 patients registered (as of September 2015) at a multisite general practice, in the borough of Greenwich, South East London. The records included patient demographic information, previous long-term condition diagnoses, a neighbourhood indicator and a unique household identifier. Long-term conditions were identified from the general practitioner (GP) record using Quality and Outcomes Framework (QOF) read codes; these included arterial fibrillation, asthma, cancer, chronic heart disease, chronic kidney disease, chronic obstructive pulmonary disease, dementia, depression and/or anxiety, diabetes, epilepsy, heart failure, hypertension, a learning disability, a mental health condition (schizophrenia, bipolar affective disorder and other psychoses), osteoarthritis, osteoporosis, peripheral artery disease, palliative care, rheumatoid arthritis and stroke or transient ischaemic attack. ${ }^{24}$

Full details of the date and type of general practice appointments were available. Utilisation counts of secondary care services (emergency department attendances, inpatient admissions and outpatient appointments) were also available; these secondary care data were reported to the general practice by secondary care providers, and then recorded on patient electronic health records by well-trained coders.

We extracted information on the healthcare utilisation of all patients from 22 September 2015 to 21 September 2016. Patients living at the same address were identified using the unique household identifier. We defined 'children and young people' (CYP) as patients under the age of 16 years, and 'parents' as patients aged 18-55 years. Our cohort of interest were all children and parents in households with at least one 'CYP' and one 'parent' where a 'parent' is any parent, carer or adult living in the household. Patients aged 16 and 17 years were excluded from this analysis. Furthermore, any person living at the same address that was not registered at the general practice was not included in this analysis.

\section{Outcomes}

Four different outcomes were investigated relating to CYP's utilisation of healthcare services in primary and secondary care over the year: the number of general practice appointments, and any emergency department attendance, inpatient admission and outpatient appointment.

\section{Covariates}

The observed CYP characteristics were age, sex, socioeconomic deprivation and diagnosis of any long-term conditions using Quality and Outcomes Framework (QOF) read codes. We categorised age into three groups: ' $0-5$ ', ' $6-10$ ' and ' $11-15$ '. To determine a CYP's socioeconomic status, we used the neighbourhood indicator associated with their household's address and ranked the 2010 index of multiple deprivation scores to produce five quintiles (with 1 being the most deprived and 5 the least). An indicator variable was used to show whether a CYP had any long-term conditions present on their electronic health record, which were assigned from clinical notes by clinical coders at the practice.

Parental characteristics were mean age, mean count of healthcare utilisation and presence of long-term conditions; these variables were all calculated at the household level, using information from all parents. 
To avoid data sparsity issues, only common long-term conditions which were present in the parents of at least 50 CYP were reported on and used in our model. For each CYP healthcare utilisation outcome modelled, the appropriate mean parental healthcare utilisation variable was included in the model.

Household characteristics included the number of adults aged 18-55 years (' 1 ' or ' $2+$ '), the number of CYP aged $0-15$ years, the presence of any patient aged 65 years and over and the total number of patients in the household.

\section{Statistical methods}

Adjusting for CYP characteristics, parental long-term conditions and mean parental healthcare utilisation, we used multivariable generalised linear models ${ }^{25}$ to examine the association between CYP healthcare utilisation and the characteristics of the CYP, their parents and their household structure, including clustering of behaviour among CYP with siblings. ${ }^{26}{ }^{27}$ Rate and Odds Ratios (ORs) were produced to interpret the results. Further details on statistical methods used can be found in online supplementary appendix 1.

\section{Subgroup analysis}

To examine the different effects of the covariates across different age groups, a subgroup analysis was performed. The model was run on three different subgroups of CYP, the first only included those aged 5 years or younger, the second only included those between aged 6 and 10 years and the third included those aged between 11 and 15 years.

\section{Sensitivity analysis}

We performed two sensitivity analyses. The first restricted our analysis to examining the impact of characteristics of female adults in the household, in order to see whether maternal rather than parental health has different associations with CYP health. Finally, we increased the thresholds for our secondary care outcomes to at least two instances of use to determine whether the model is robust at higher levels of utilisation and to determine whether there were any notable changes (including statistically significant changes) in the results.

\section{Ethics statement}

Routinely collected, retrospective, pseudonymised data were used for this analysis, with a data sharing agreement approved by the Valentine Health data holders. Data were analysed as part of an audit and quality improvement initiative with Valentine Health. No furthers ethics approval was required.

\section{RESULTS}

There were 6738 CYP (aged 0-15 years) in the dataset; 614 did not live with an adult (aged 18-55 years) leaving 6124 CYP in our analysis cohort living in 3373 households. Where a CYP was identified as living with no adult, based on the opinion of the practice staff, we assumed the adults were registered at other practices. Forty-one per cent (2485) of the CYP lived in households with one potential parent, $41 \%$ (2503) with two and 19\% (1136) with three or more adults between 18 and 55 . Seventy-four per cent (4519) CYP had siblings and 26\% (1605) CYP did not. The most common parental long-term condition was depression (depression and/or anxiety), with 16\% (980) of CYP having a diagnosed parent (see table 1).

A full description of the characteristics of the CYP cohort is provided in supplementary appendix $2-4$. Seventy-four per cent (4510) of CYP had at least one general practice appointment, and the mean number of appointments was 2.7 (SD 3.3). In the study year, 20\% (1203) of CYP had an emergency department attendance, 9\% (562) an inpatient admission and 18\% (1114) an outpatient appointment (see online supplementary appendix 3). Six per cent (395) of CYP had at least one long-term condition (see online supplementary appendix 3 ).

Characteristics for children with siblings are not notably different to characteristics of children without siblings, and results from modelling CYP with siblings and CYP without siblings were consistent. For the purposes of brevity, only results for CYP with siblings are reported on here, but results for CYP without siblings are available as supplementary material. The best fitting models for each outcome of interest, including inpatient admissions and outpatient appointments, are given in online supplementary appendix 5.

When controlling for the characteristics of CYP only (model 1), we found that being older and not having any long-term condition diagnoses was significantly associated with reduced utilisation of all four types of healthcare $(\mathrm{p}<0.01)$ (see tables 2 and 3, and online supplementary appendix 6).

Controlling for other CYP and parental characteristics (model 2), parental healthcare utilisation was associated with increased CYP healthcare utilisation across all four healthcare services: general practice rate ratio: 1.07 (95\% CI 1.06 to 1.08); emergency department attendance OR: 1.27 (95\% CI 1.12 to 1.44); inpatient admission OR: 1.43 (95\% CI 1.06 to 1.93 ); and outpatient attendance OR: 1.08 (95\% CI 101 to 1.15). For example, a one point increase in parental emergency department utilisation is associated with a $27 \%$ increased odds of child emergency department attendance. Parental depression (vs not) was positively associated for all secondary care utilisation, with OR for emergency department attendance 1.41 (95\% CI 1.10 to 1.80 ), inpatient admissions 1.47 (95\% CI 1.07 to 2.03) and outpatient appointments 1.67 (95\% CI 1.32 to 2.11). A parental diagnosis of osteoarthritis was positively associated with increased attendance at general practice, rate ratio of 1.24 (95\% CI 1.01 to 1.52 ) (see tables 2 and 3 , and online supplementary appendix 7).

In CYP aged 11-15 years, the association between parental depression and general practice utilisation was significant and stronger than in the younger age groups (rate ratio: 1.28 (96\% CI 1.04 to 1.57$)$ ). A similar 


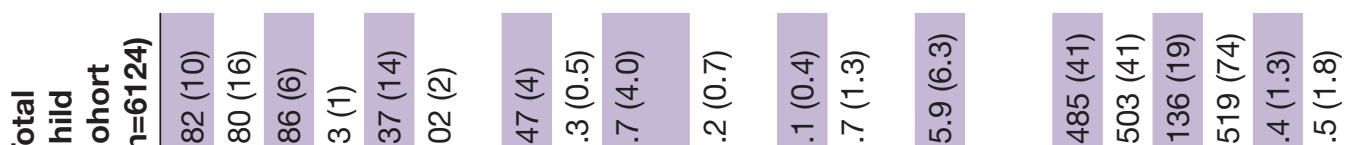

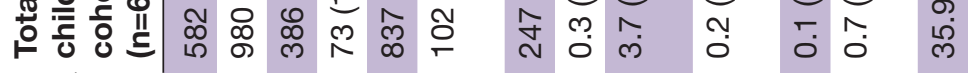

ᄂ 永

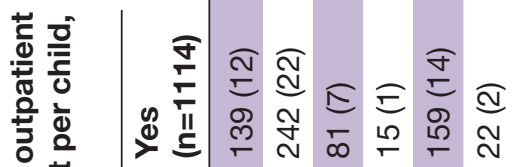

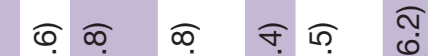

एक

สิ่

गु

ग)

ธั

ก

하

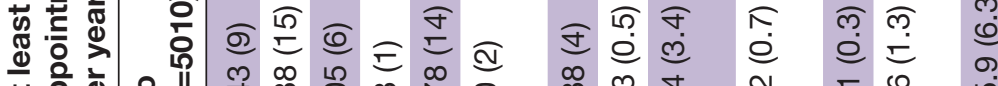

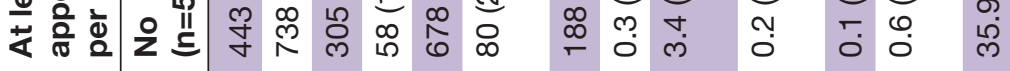

守过

กิ

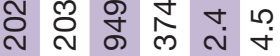

$+\frac{\grave{d}}{\square}$

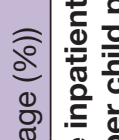

สิธ ชิ

$\widehat{0}$

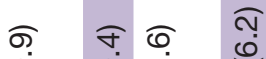

守

$\infty$ a 0 N

N $N$ N

艺

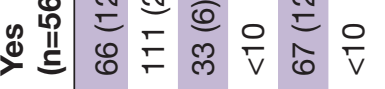

$\sim \infty$

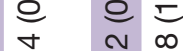

ले

焉

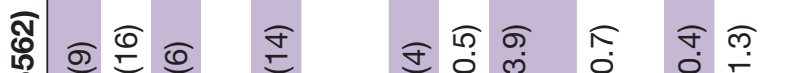

ตุ

空

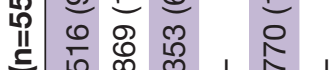

-

c

लें

항

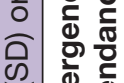

ช్ ָิ

ลูก

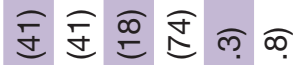

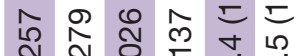

ก กิ

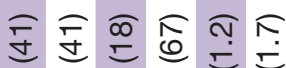

ᄋ

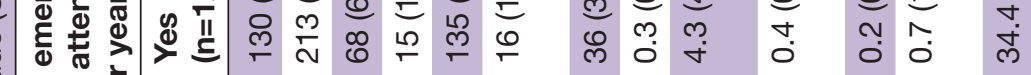

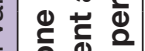

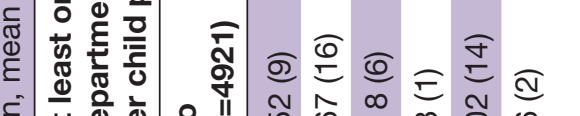

त० ब ल ल ल

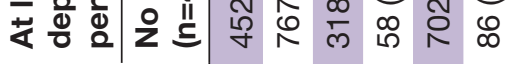

土过

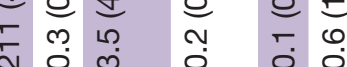

ก

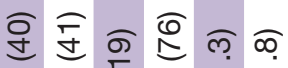

क

赵

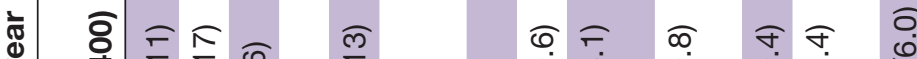

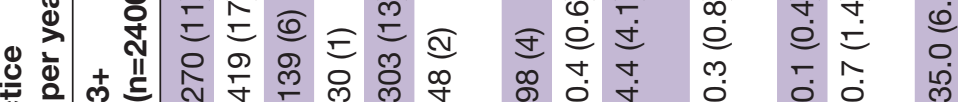

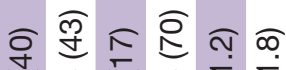

I $\infty=\infty \sum$

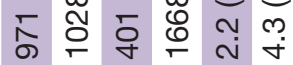

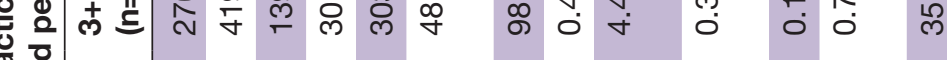

ฮิ จิ

过昌的品

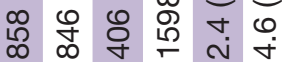

至

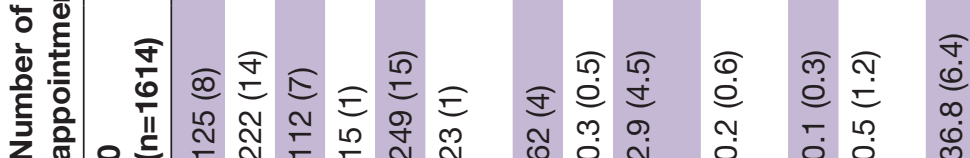

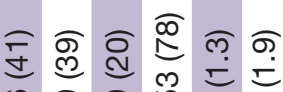

L

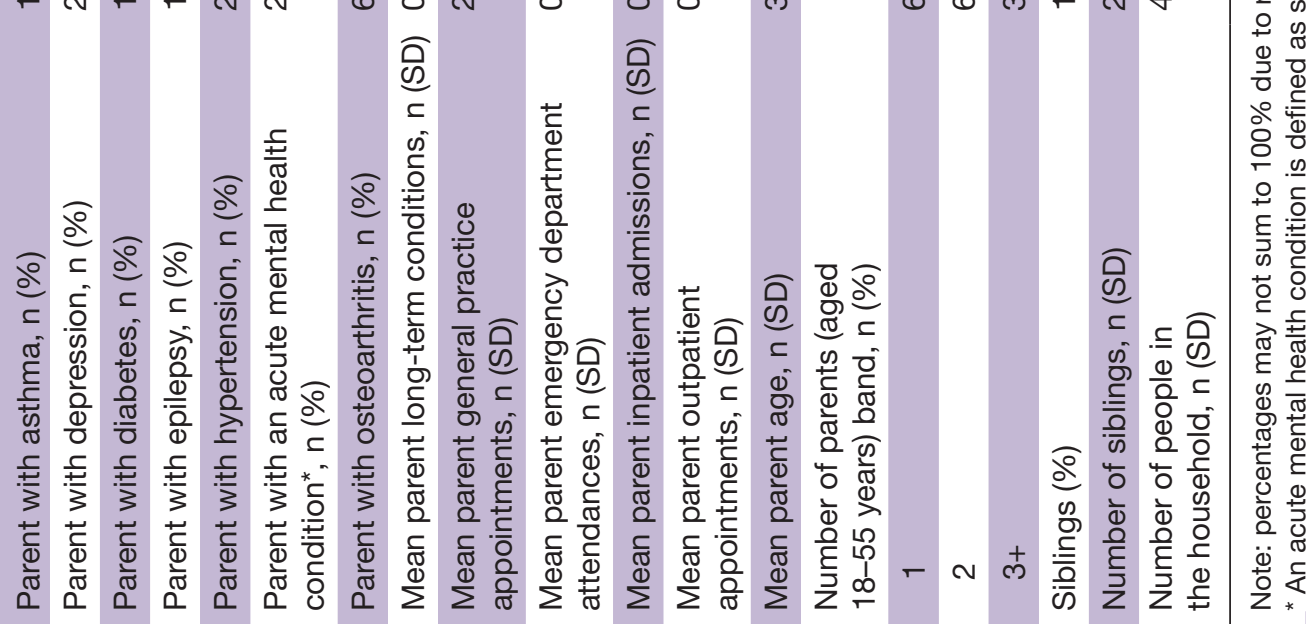


Table 2 Poisson regression models predicting child general practice utilisation

\begin{tabular}{|c|c|c|c|c|}
\hline & \multicolumn{4}{|c|}{ Children with siblings ( $n=4519$ ) } \\
\hline & \multicolumn{2}{|l|}{ Model 1} & \multicolumn{2}{|l|}{ Model 2} \\
\hline & Rate ratio $(95 \% \mathrm{Cl})$ & $P$ values & Rate ratio $(95 \% \mathrm{Cl})$ & $P$ values \\
\hline \multicolumn{5}{|l|}{ Child characteristics } \\
\hline \multicolumn{5}{|l|}{ Child age band (vs 0-5) } \\
\hline $6-10$ & $0.42(0.40$ to 0.44$)$ & $<0.001$ & $0.42(0.40$ to 0.44$)$ & $<0.001$ \\
\hline $11-15$ & 0.39 (0.37 to 0.42$)$ & $<0.001$ & 0.39 (0.37 to 0.42$)$ & $<0.001$ \\
\hline Child female (vs male) & $1.02(0.97$ to 1.07$)$ & 0.421 & $1.02(0.97$ to 1.07$)$ & 0.392 \\
\hline \multicolumn{5}{|c|}{$\begin{array}{l}\text { Child Index of Multiple Deprivation (IMD) quintile } \\
\text { (vs 1) }\end{array}$} \\
\hline 2 & $0.93(0.82$ to 1.06$)$ & 0.265 & $0.98(0.87$ to 1.11$)$ & 0.773 \\
\hline 3 & 0.97 (0.86 to 1.11$)$ & 0.676 & $1.02(0.90$ to 1.15$)$ & 0.753 \\
\hline 4 & 0.99 (0.87 to 1.12$)$ & 0.862 & 1.03 (0.91 to 1.16$)$ & 0.648 \\
\hline 5 & 0.95 (0.83 to 1.07$)$ & 0.390 & 1.00 (0.88 to 1.12$)$ & 0.944 \\
\hline Child long-term condition (vs not) & 1.96 (1.80 to 2.14$)$ & $<0.001$ & 1.91 (1.75 to 2.09$)$ & $<0.001$ \\
\hline \multicolumn{5}{|l|}{ Parent characteristics } \\
\hline Parent with asthma (vs not) & - & - & 1.05 (0.92 to 1.19$)$ & 0.500 \\
\hline Parent with depression (vs not) & - & - & 1.08 (0.97 to 1.19$)$ & 0.162 \\
\hline Parent with diabetes (vs not) & - & - & 0.91 (0.77 to 1.07$)$ & 0.234 \\
\hline Parent with epilepsy (vs not) & - & - & $1.08(0.74$ to 1.56$)$ & 0.701 \\
\hline Parent with hypertension (vs not) & - & - & $0.93(0.83$ to 1.05$)$ & 0.230 \\
\hline Parent with a mental health condition (vs not) & - & - & 0.99 (0.74 to 1.34$)$ & 0.964 \\
\hline Parent with osteoarthritis (vs not) & - & - & 1.24 (1.01 to 1.52$)$ & 0.036 \\
\hline Parent general practice appointments & - & - & 1.07 (1.06 to 1.08$)$ & $<0.001$ \\
\hline
\end{tabular}

Models first control for just child characteristics (model 1), and then both child and parent characteristics (model 2).

trend can be seen in outpatient utilisation with OR 2.13 (95\% CI 1.38 to 3.27 ) for children aged $11-15$ years (see online supplementary appendix 7). Although not significant, the same trend can be seen for emergency department attendances. The association between osteoarthritis and general practice appointments was consistent with the main results; however, the subgroup analysis did not inform any specific trends as the sample size of the subgroup by age was too small. Further research is needed to understand what is driving the association between osteoarthritis and general practice utilisation. Samples size was too small to conduct a subgroup analysis for CYP without siblings.

Our findings from the sensitivity analyses, which included restricting parental characteristics to maternal characteristics only, and increasing the thresholds for our secondary care outcomes, were consistent with our main results (see supplementary appendix 8 and 9).

\section{DISCUSSION}

Parental depression was associated with a statistically significant increase in secondary care utilisation. We also found that parental and CYP healthcare utilisation were associated in both primary and secondary care.
The mechanism behind this association is complex, bidirectional and likely to be a combination of factors, including increased parental perception of vulnerability of the CYP, recognising a need for medical support from the health system, ${ }^{10}$ a lack of social support ${ }^{28}$ and underlying patterns of parental behaviour. ${ }^{13}$ For example, parental anxiety is well recognised as a contributing factor in healthcare-seeking behaviour, especially for young children. ${ }^{15}$ However, parental depression may also be a consequence of prolonged illness in a child. For parents with depression, our findings highlight the wider impact mental health conditions have on outcomes for families and paediatric care and the potential benefits to those suffering from depression from proposed increased investment in mental health services. ${ }^{29}$

To our knowledge, there have only been two studies examining the general healthcare utilisation of CYP in relation to their parents in the National Health Service; one of which was quantitative which found that living with an adult with a mental health condition was associated with a $17 \%$ increase in emergency admissions. ${ }^{30} 31$ Our results are consistent with findings from previous international studies, with one paper finding that parental depression was associated with between a $15 \%$ 
Table 3 Logistic regression models predicting child emergency department utilisation

\begin{tabular}{|c|c|c|c|c|}
\hline & \multicolumn{4}{|c|}{ Children with siblings $(n=4519)$} \\
\hline & \multicolumn{2}{|l|}{ Model 1} & \multicolumn{2}{|l|}{ Model 2} \\
\hline & OR $(95 \% \mathrm{Cl})$ & $P$ values & OR $(95 \% \mathrm{Cl})$ & $P$ values \\
\hline \multicolumn{5}{|l|}{ Child characteristics } \\
\hline \multicolumn{5}{|l|}{ Child age band (vs 0 to 5 ) } \\
\hline $6-10$ & 0.18 (0.14 to 0.22$)$ & $<0.001$ & 0.18 (0.14 to 0.22$)$ & $<0.001$ \\
\hline $11-15$ & 0.19 (0.15 to 0.25$)$ & $<0.001$ & 0.19 (0.15 to 0.25$)$ & $<0.001$ \\
\hline Child female (vs male) & 0.75 (0.63 to 0.89$)$ & 0.001 & 0.74 (0.62 to 0.88$)$ & $<0.001$ \\
\hline \multicolumn{5}{|l|}{$\begin{array}{l}\text { Child Index of Multiple Deprivation (IMD) } \\
\text { quintile (vs 1) }\end{array}$} \\
\hline 2 & 1.02 (0.77 to 1.37$)$ & 0.872 & 1.06 (0.79 to 1.41$)$ & 0.711 \\
\hline 3 & 0.91 (0.67 to 1.23$)$ & 0.521 & 0.95 (0.70 to 1.29$)$ & 0.748 \\
\hline 4 & 0.96 (0.71 to 1.30$)$ & 0.791 & 0.99 (0.73 to 1.34$)$ & 0.949 \\
\hline 5 & 1.05 (0.78 to 1.41$)$ & 0.766 & 1.07 (0.80 to 1.45$)$ & 0.635 \\
\hline Child long-term condition (vs not) & 2.64 (1.88 to 3.71$)$ & $<0.001$ & 2.58 (1.84 to 3.63 ) & $<0.001$ \\
\hline \multicolumn{5}{|l|}{ Parent characteristics } \\
\hline Parent with asthma (vs not) & - & - & 0.95 (0.68 to 1.31$)$ & 0.741 \\
\hline Parent with depression (vs not) & - & - & $1.41(1.10$ to 1.80$)$ & 0.007 \\
\hline Parent with diabetes (vs not) & - & - & 0.97 (0.64 to 1.46$)$ & 0.872 \\
\hline Parent with epilepsy (vs not) & - & - & 1.17 (0.48 to 2.85$)$ & 0.728 \\
\hline Parent with hypertension (vs not) & - & - & 0.86 (0.64 to 1.15$)$ & 0.310 \\
\hline Parent with a mental health condition (vs not) & - & - & 0.67 (0.31 to 1.46$)$ & 0.319 \\
\hline Parent with osteoarthritis (vs not) & - & - & 0.95 (0.56 to 1.62$)$ & 0.860 \\
\hline Parent emergency department attendance & - & - & 1.27 (1.12 to 1.44$)$ & $<0.001$ \\
\hline
\end{tabular}

Models first control for just child characteristics (model 1), and then both child and parent characteristics (model 2).

and $35 \%$ increase in emergency department attendances for children. ${ }^{1023}$ In contrast, studies that examined both parental healthcare utilisation and self-reported measures of parental health have found that parental health is not associated with child healthcare utilisation. ${ }^{132132}$

This study has a number of strengths. We analysed the electronic health records of all registered patients at a large general practice and did not rely on self-reported healthcare utilisation. As the practice provides care to all residents in the local area and is free at the point of use, it provides a unique insight into family and community structures within its catchment area. The completeness of our sample means that we were properly able to account for those registered with the practice and accurately include parental diagnoses of long-term conditions, as well as accurately account for healthcare utilisation. We also benefited from being able to analyse all children in a household at the same time, taking account of clustering at the household level in order to more accurately examine the impact of parental health.

A number of limitations of this study should be noted. Patients are all registered at, and live in the proximity of, one general practice in South East London, and there may be area-level effects or specific policies at this general practice that influence patient behaviour. As a result, this cohort may not be representative of the general population. This impacts the generalisability of these results to other areas across the country. The sample size limited our ability to perform subgroup and sensitivity analyses and to detect significance of parental conditions in models of families with no siblings. We classified all patients living at a single address as families and as being either a parent or a child; however, there may be multiple families at a single address or unrelated people that are included in the analysis. The number of parental long-term conditions across households is low due to the sample size, which reduces the power of our models. As a result, conditions, which may be significant in predicting healthcare utilisation in CYP, may not be identified. Secondary care data were reported to the general practice by secondary care providers; there is a risk that some secondary care utilisation is unreported. Furthermore, although the dataset was comprehensive, there are several factors that were not available, including social support, either through grandparents or other family living in the area but not living in the household or through more formal structures. Each of these factors may influence both healthcare utilisation and children's health outcomes. Finally, we were only aware of patients registered at the practice, so our households may be missing people who live there that are not registered or 
are registered at another practice. While we would expect all CYP to be registered at a general practice, and CYP in the same household to be registered at the same practice as their parents, we could be missing parents, especially those with no long-term conditions or healthcare utilisation and families with parental disharmony where parents live in different areas.

Our research demonstrates the utility of the household linkage and its clinical relevance; further research is needed on a fully linked dataset across the health economy, which also contained information on household structure (including but not limited to a maternal link).

Parental long-term conditions are a predictor of CYP utilisation of secondary healthcare services, in particular parental depression is a predictor of emergency admissions for CYP. The results presented in this paper suggest that a holistic assessment of family needs, particularly parental mental health and social support, may be an effective approach to improving the health and well-being of CYP. A number of studies have provided evidence of the benefits of integrated care on meeting patient needs and managing the demand for healthcare services. ${ }^{633} 34$ Innovative models of integrated care, such as Connecting Care for Children, ${ }^{33}$ may be able to facilitate family appointments that allow for an authoritative diagnosis or reassurance about the child's medical needs, while taking account of parental health and family needs. Strong primary and social care provision for a whole family could provide efficacious and efficient care, increasing equity in health outcomes for children.

Acknowledgements We would like to thank Isaac Barker at the Health Foundation for his direction during initial data analysis and study conception. Also, we would like to thank the Data Management Team for their work managing the data sharing process, especially at short notice.

Contributors SRD and RAPW conceived the study. SRD and RAPW designed the statistical analysis plan. RR prepared the data extract. KD and RAPW carried out the analysis. All authors drafted and finalised the paper.

Funding This study was funded as part of the core activities of the Health Foundation. The corresponding author had full access to all data in the study and final responsibility for the decision to submit.

Disclaimer The funding body had no role in the design of the study; collection, analysis or interpretation of data; writing the manuscript; or decision to submit.

Competing interests None declared.

Patient consent Not required.

Ethics approval This study meets national guidelines set out by the Research Ethics Service for the National Health Service in England.

Provenance and peer review Not commissioned; externally peer reviewed.

Data sharing statement The data that support the findings of this study are available from Valentine Health but restrictions apply to the availability of these data, which were used under a data sharing agreement for the current study, and so are not publicly available. Data are, however, available from the authors on reasonable request and with permission of Valentine Health.

Open access This is an open access article distributed in accordance with the Creative Commons Attribution Non Commercial (CC BY-NC 4.0) license, which permits others to distribute, remix, adapt, build upon this work non-commercially, and license their derivative works on different terms, provided the original work is properly cited and the use is non-commercial. See: http://creativecommons.org/ licenses/by-nc/4.0/ (c) Article author(s) (or their employer(s) unless otherwise stated in the text of the article) 2018. All rights reserved. No commercial use is permitted unless otherwise expressly granted.

\section{REFERENCES}

1. Keeble E, Kossarova L. Focus on: Emergency hospital care for children and young people About QualityWatch. 2017 http://www. qualitywatch.org.uk/sites/files/qualitywatch/field/field_document/ QualityWatch CYP report.pdf (accessed 23 Nov 2017).

2. Wahl H, Banerjee J, Manikam L, et al. Health information needs of families attending the paediatric emergency department. Arch Dis Child 2011;96:335-9.

3. Institute for Innovation and Improvement. $A$ whole system approach to improving emergency and urgent care for children and young people, 2011.

4. Cowling TE, Cecil EV, Soljak MA, et al. Access to primary care and visits to emergency departments in England: a cross-sectional, population-based study. PLoS One 2013;8:e66699.

5. Ismail SA, Gibbons DC, Gnani S. Reducing inappropriate accident and emergency department attendances: a systematic review of primary care service interventions. Br J Gen Pract 2013;63:e813-20.

6. Viner RM, Hargreaves DS. A forward view for child health: integrating across the system to improve health and reduce hospital attendances for children and young people. Arch Dis Child 2018;103:archdischild-2017-314032.

7. Cheung CR, Gray JA. Unwarranted variation in health care for children and young people. Arch Dis Child 2013;98:60-5.

8. Rudge GM, Mohammed MA, Fillingham SC, et al. The combined influence of distance and neighbourhood deprivation on emergency department attendance in a large english population: a retrospective database study. PLoS One 2013;8:e6794.

9. Cecil E, Bottle A, Cowling TE, et al. Primary care access, emergency department visits, and unplanned short hospitalizations in the UK. Pediatrics 2016;137.

10. Mandl KD, Tronick EZ, Brennan TA, et al. Infant health care use and maternal depression. Arch Pediatr Adolesc Med 1999;153:808-13.

11. Turney K. Maternal depression and childhood health inequalities. $J$ Health Soc Behav 2011;52:314-32.

12. Harron K, Gilbert R, Cromwell D, et al. Adversity and risk of poor birth and infant outcomes for young mothers: a population-based data-linkage cohort study. Lancet. 2016;388:S54.

13. Hanson KL. Is insurance for children enough? The link between parents' and children's health care use revisited. Inquiry 1998;35:294-302.

14. Smith M. Parental mental health: disruptions to parenting and outcomes for children. Child Fam Soc Work 2004;9:3-11.

15. Rowe B, Cook C, Wootton R, et al. A\&amp;E: Studying parental decision making around non-urgent attendance among under $5 \mathrm{~s}$. 2015 https://www.revealingreality.co.uk/wp-content/uploads/2017/ 03/Revealing_Reality_DH_non-urgent_attendance.pdf (accessed 10 Apr 2018).

16. Center on the Developing Child. The foundations of lifelong health are built in early childhood, 2010.

17. Kinsman AM, Wildman BG, Smucker WD. Brief report: parent report about health care use: relationship to child's and parent's psychosocial problems. J Pediatr Psychol 1999;24:435-9.

18. Loiselle KA, Lee JL, Gilleland J, et al. Factors associated with healthcare utilization among children with noncardiac chest pain and innocent heart murmurs. J Pediatr Psychol 2012;37:817-25.

19. Lipstein EA, Perrin JM, Kuhlthau KA. School absenteeism, health status, and health care utilization among children with asthma: associations with parental chronic disease. Pediatrics 2009;123:e60-6.

20. Hardie JH, Landale NS. Profiles of risk: maternal health, socioeconomic status, and child health. J Marriage Fam 2013;75:651-66.

21. Minkovitz CS, O'Campo PJ, Chen YH, et al. Associations between maternal and child health status and patterns of medical care use. Ambul Pediatr 2002;2:85-92.

22. Garbarski $D$. The interplay between child and maternal health: reciprocal relationships and cumulative disadvantage during childhood and adolescence. J Health Soc Behav 2014;55:91-106.

23. Sills MR, Shetterly S, Xu S, et al. Association between parental depression and children's health care use. Pediatrics 2007;119:e829-36.

24. The National Archives. 2014/15 General Medical Services (GMS) Contract Quality and Outcomes Framework (QOF). 2015 http:// content.digital.nhs.uk/media/22803/2015-16-QOF-guidancedocuments/pdf/2015-16_QOF_guidance_documents_.pdf 
25. Goldstein H. Multilevel statistical models. Chichester, UK: John Wiley \& Sons, Ltd, 2010.

26. Dundas R, Leyland AH, Macintyre S. Early-life school, neighborhood, and family influences on adult health: a multilevel cross-classified analysis of the Aberdeen children of the 1950s study. Am J Epidemiol 2014;180:197-207.

27. Rasbash J, Leckie G, Pillinger R, et al. Children's educational progress: partitioning family, school and area effects. $J R$ Stat Soc Ser A Stat Soc 2010;173:657-82.

28. Kouzis AC, Eaton WW. Absence of social networks, social support and health services utilization. Psychol Med 1998;28:1301-10.

29. NHS England. Five year forward view for mental health: one year on, 2017.

30. Gronholm PC, Ford T, Roberts RE, et al. Mental health service use by young people: the role of caregiver characteristics. PLoS One 2015;10:e0120004.
31 Paranjothy S, Evans A, Bandyopadhyay A, et al. Risk of emergency hospital admission in children associated with mental disorders and alcohol misuse in the household: an electronic birth cohort study. Lancet Public Health 2018;3:e279-e288.

32 Mistry RD, Hoffmann RG, Yauck JS, et al. Association between parental and childhood emergency department utilization. Pediatrics 2005;115:e147-51.

33 Zhang Y, Zhou Z, Si Y. The role of parental health care utilization in children's unnecessary utilization in China: Evidence from Shaanxi province. Int J Equity Health 2017;16:1180.

34 Montgomery-Taylor S, Watson M, Klaber R. Child health general practice hubs: a service evaluation. Arch Dis Child 2016;101:333-7.

35 Klaber B. It is time to think differently about outpatients? 2017 https://www.nuffieldtrust.org.uk/news-item/is-it-time-to-thinkdifferently-about-outpatients\#getting-in-the-way-of-change (accessed 4 Jan 2018). 